\title{
Endoglina: estructura, funciones biológicas y papel en la fibrogénesis
}

\author{
L. García-Pozo, M. E. Miquilena-Colina, T. Lozano-Rodríguez y C. García-Monzón \\ Unidad de Investigación Hepática. Hospital Universitario Santa Cristina. Centro de Investigación Médica en Red de \\ enfermedades hepáticas y digestivas (CIBERehd). Madrid
}

García-Pozo L, Miquilena-Colina ME, Lozano-Rodríguez T, García-Monzón C. Endoglina: estructura, funciones biológicas y papel en la fibrogénesis. Rev Esp Enferm Dig 2008; 100: 355-360.

\section{INTRODUCCIÓN}

La endoglina, también llamada CD105, se descubrió a finales de la década de 1980 como un marcador de células endoteliales humanas mediante un anticuerpo monoclonal, llamado 44G4, creado para combatir una línea de células leucémicas pre-B (1). Otros estudios mostraron que la endoglina se expresaba también en los macrófagos, los precursores eritroides, los sincitiotrofoblastos de la placenta terminal y en las células del estroma (2-5). El gen que codifica la endoglina se ha localizado en el brazo largo del cromosoma humano 9 (6) y las mutaciones de este gen son las responsables de un trastorno vascular autosómico dominante que se denomina telangiectasia hemorrágica hereditaria de tipo 1 (THH1) (7). La endoglina se une con gran afinidad a distintas isoformas del TGF- $\beta$ en las células del endotelio (CE) humano (8) y desempeña un papel importante en la angiogénesis (9), pues los ratones con desactivación homozigótica del gen de la endoglina mueren en medio de la gestación por angiogénesis defectuosa y anomalías cardiovasculares graves, mientras que los heterozigóticos son viables, aunque están predispuestos a tener anomalías vasculares parecidas a la THH (10-12).

\section{Recibido: 04-03-08.}

Aceptado: 08-03-08.

Correspondencia: Carmelo García Monzón. Unidad de Investigación Hepática. Hospital Universitario Santa Cristina. Maestro Vives, 2. 28009 Madrid.e-mail: cgarcia.hscr@salud.madrid.org
Aparte de su importancia biológica en procesos fundamentales de las células endoteliales, el reconocimiento de la relevancia que posee la endoglina en medicina es cada vez mayor. En ese sentido, estudios tanto in vitro como in vivo han confirmado el enorme potencial de la endoglina como diana terapéutica del cáncer humano, observándose que los anticuerpos monoconales anti-CD105 conjugados con inmunotoxinas inducen supresiones duraderas del crecimiento tumoral y las metástasis en los modelos oncológicos animales $(13,14)$. Por otra parte, cada vez son más las pruebas de que la endoglina podría desempeñar un papel importante en la fibrogénesis, ya que se ha observado una sobreexpresión de esta proteína en biopsias de pacientes con fibrosis renal y hepática $(15,16)$. Esta revisión resume algunos de los últimos avances en el conocimiento de la estructura y las funciones biológicas de la endoglina, haciendo especial énfasis en su posible papel en la fibrogénesis.

\section{ESTRUCTURA}

La endoglina es una glicoproteína homodimérica transmembranosa de $180 \mathrm{kDa}$ que contiene un dominio extracelular de 561 residuos aminoacídicos y una región citoplasmática rica en serina y treonina de 47 residuos aminoacídicos $(17,18)$. Estructuralmente, la endoglina pertenece a la familia de proteínas extracelulares de la zona pelúcida $(\mathrm{ZP})$, que poseen en común un do- 
minio ZP de unos 260 aminoácidos con 8 residuos cisteínicos conservados próximos a la región transmembranosa $(19,20)$. Además se han detectado motivos consensuados en la secuencia de aminoácidos de la endoglina, incluidos un motivo de fijación celular RGD en la posición $\operatorname{Arg} 399-A s p 401(21,22)$ y una serie de puntos de glicosilación de tipo O y N (Fig. 1). El grupo del Prof. Carmelo Bernabéu, del Centro de Investigaciones Biológicas de Madrid, ha publicado recientemente una predicción del modelo estructural 3D del dominio extracelular de la endoglina (23). Determinaron que cada monómero consta de tres dominios bien definidos. En el extremo terminal $\mathrm{N}$ hay un gran dominio que contiene los residuos de aminoácidos Glu26Ile359. Este fragmento no presenta ninguna homología significativa con las demás familias y dominios de proteínas, por lo que se le ha llamado dominio "huérfano". Después de este fragmento, la secuencia que codifica el dominio ZP (residuos aminoacídicos Gln360-Gly586) se divide en dos subdominios, de conformidad con lo publicado respecto a otros miembros de la familia ZP (20). Estos subdominios se llaman ZP-N, una región alargada que comprende los residuos de aminoácidos Gln360-Ser457, y ZP-C (residuos de aminoácidos Pro458-Gly587). Este modelo estructural de la endoglina puede emplearse como marco para delinear regiones importantes de las funciones de esta proteína.

Más de la tercera parte del dominio extracelular de la endoglina está formada por el dominio ZP, lo que indica que desempeña un papel importante en la función de la endoglina $(19,20)$. El dominio ZP está presente en mu-

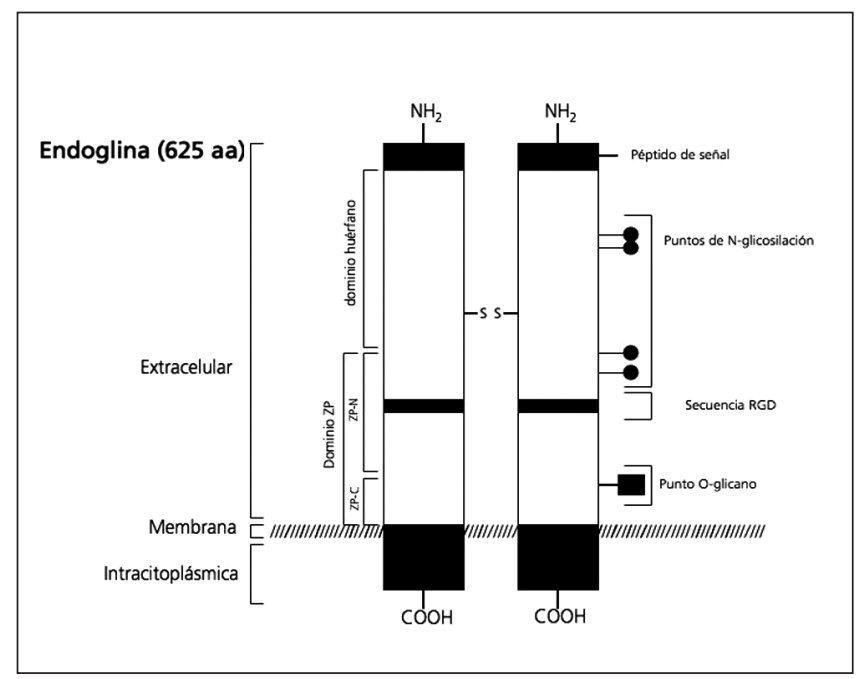

Fig. 1. Esquema de la estructura de endoglina, receptor de TGF- $\beta$ de tipo III. Cada monómero de esta glicoproteína homodimérica transmembranosa contiene un péptido señalizador $\mathrm{N}$-terminal, dos largos dominios cisteínicos extracelulares (dominio huérfano y dominio ZP), una región transmembranosa corta y un breve extremo C-terminal. Se han identificado posibles puntos de glicosilación $\mathrm{O}$ y $\mathrm{N}$ en los dominios huérfano y ZP. En el subdominio ZP-N se encuentra una secuencia RGD conservada. La endoglina humana es una proteína de 625 aminoácidos. chas proteínas situadas extracelularmente y todas ellas tienen en común con la endoglina una serie de propiedades biológicas, como: a) todas se han detectado en forma soluble; b) son proteínas de membrana que contienen un segmento hidrófobo en el extremo terminal C; c) están muy glicosiladas; y d) aparecen en grandes cantidades en sus respectivos tejidos. Las funciones de las proteínas con dominio ZP varían: van de los componentes estructurales a los receptores en mamíferos y no mamíferos. La región homóloga $\mathrm{ZP}$, de alrededor de 260 residuos, que tienen en común estas proteínas contiene ocho residuos de cisteína estrictamente conservados y que pueden formar puentes disulfuro intramoleculares. Estos módulos de cisteína de la región ZP se han conservado evolutivamente entre las endoglinas de distintas especies de mamíferos, incluidos los seres humanos, los ratones, las ratas, los cerdos y los perros.

El dominio ZP es un módulo para la polimerización de proteínas extracelulares, siendo la región terminal $\mathrm{N}$ la responsable de las interacciones entre proteínas (24). Como la endoglina forma parte del sistema receptor del TGF- $\beta$, resulta tentador especular que su dominio ZP podría intervenir en su relación heteromérica con el receptor de TGF- $\beta$ de tipo I (T $\beta R$-I) y el receptor de TGF- $\beta$ de tipo II (T $\beta R$-II), con el fin de permitir el agrupamiento y la señalización del complejo receptor del TGF- $\beta$. La posición del dominio ZP que se observa en el modelo 3D de la endoglina sería compatible con ese papel. De hecho, el dominio extracelular de la endoglina interactúa con el T $\beta R$-I y el T $\beta R$-II y la región implicada en tales interacciones (Arg437-Gly558) queda dentro del subdominio ZP-C. Además, el T $\beta R-I$ interactúa no sólo con el subdominio ZP-C, sino también con una segunda región situada entre los residuos aminoacídicos Glu26 y Arg437 y que puede localizarse dentro del subdominio ZP-N.

Las mutaciones del gen de la endoglina son las responsables de la THH1, un trastorno autosómico dominante. La haploinsuficiencia parece estar en la raíz del mecanismo patogénico de la THH1, pues los alelos mutantes dejan simplemente de expresarse en la célula endotelial, lo que conduce a la hipótesis de que las mutaciones de la endoglina constituyen alelos no funcionantes (25). Entre las distintas mutaciones de la endoglina, y agrupadas en los exones que codifican el dominio extracelular, el grupo de las mutaciones sin sentido tiene interés estructural, pues podrían ayudar a comprender por qué la proteína mutante no se expresa en la superficie celular (25). $\mathrm{Cu}$ riosamente, la mayoría de estas mutaciones no se distribuían de manera aleatoria por toda la región extracelular, sino que se situaban dentro del dominio huérfano o el subdominio ZP-N yuxtapuesto. En particular, tres de los cuatro residuos de cisteína que se conservan en el subdominio ZP-N (Cys363, Cys382 y Cys412) se vio que estaban mutados en la THH1. En general, los aminoácidos concretos que aparecen mutados en los pacientes con THH1 están muy conservados en las endoglinas de especies distintas, lo que indica que los módulos proteicos 
que contienen estos residuos mutados, principalmente el dominio huérfano y el subdominio ZP-N, son estructuras críticas para la correcta expresión de la endoglina madura en la superficie celular (23).

\section{FUNCIONES BIOLÓGICAS}

En los últimos cinco años se ha avanzado enormemente en la comprensión del papel funcional de la endoglina, en gran medida gracias al mejor conocimiento de los rasgos estructurales de la endoglina que se han resumido en el apartado anterior. Actualmente, una serie de estudios clínicos indican que las mutaciones de la endoglina producen la THH1 y que esta constituye un potente marcador de la neovascularización que se asocia a los tumores. Desde un punto de vista experimental, se ha demostrado claramente que la endoglina resulta esencial para la señalización del TGF- $\beta$ en las células endoteliales (CE), pues es capaz de modular las respuestas celulares al TGF- $\beta 1$ (26), y que interviene activamente en el proceso angiogénico al antagonizar el efecto inhibitorio del TGF- $\beta 1$ sobre las CE de la vasculatura humana (11). Más aun, la señalización del TGF- $\beta$ se ve gravemente alterada en las CE que carecen de endoglina (27), lo que da lugar a anomalías angiogénicas significativas (28) y avala contundentemente el papel fundamental de esta glicoproteína de membrana en la regulación de los efectos fisiológicos mediados por el TGF- $\beta$ en las CE.

\section{Endoglina y THH}

Se han identificado distintos loci cromosómicos y genes que aparecen mutados en los pacientes con THH. El primer locus se localizó en el cromosoma 9q33-34 mediante estudios de ligamiento $(29,30)$. Anteriormente, el grupo de Carmelo Bernabéu localizó el gen de la endoglina humana en el cromosoma 9q33-34 (6); después, McAllister y cols. (7) mostraron que el gen de la endoglina era en realidad el gen de la THH y que las mutaciones del gen de la endoglina daban lugar a la aparición de la THH de tipo 1. Es más, en varias familias con rasgos clínicos de la $\mathrm{THH}$ ligados al $12 \mathrm{q}$ se demostró posteriormente que las mutaciones del gen ALK1, localizado en el cromosoma 12q11-14, producían una segunda forma de THH, la llamada de tipo 2 (31). Recientemente se ha descrito un tercer locus, el 5q31.3-5q32, como el responsable de la THH de tipo 3 (32). Resulta interesante observar que todos los genes hallados en los pacientes con THH codifican proteínas que pertenecen a la ruta señalizadora del TGF- $\beta$.

\section{Endoglina y señalización del TGF- $\beta$}

En la señalización del TGF- $\beta$ se han involucrado un T $\beta$ R-II y dos T $\beta$ R-I distintos, la quinasa similar al receptor de activina restringida al endotelio (ALK)1 y la
ALK5, de expresión muy extendida. Los ligandos TGF- $\beta$ son muy afines por el receptor de tipo II y, al unirse al mismo, se recluta un receptor de tipo I específico. Una vez formado este complejo heteromérico de dos receptores de tipo I y dos receptores de tipo II (33), se produce la activación de los receptores de tipo I y, posteriormente, la fosforilación de unas moléculas señalizadoras llamadas Smad, que propagan la señal al núcleo (34). Las proteínas Smad son efectores nucleares de los receptores de TGF$\beta$. Hay tres tipos diferentes de proteínas Smad: las reguladas por receptores $(\mathrm{R})$, las mediadoras comunes (Co) y las inhibitorias (I). Las R-Smad, llamadas Smad1, Smad2, Smad3, Smad5 y Smad8, son fosforiladas por el receptor de tipo I, ya sea por ALK1 o ALK5 (35). ALK1, a través de los factores de transcripción Smad1, Smad5 y Smad8, induce la proliferación y migración de las $\mathrm{CE}$, mientras que ALK5, a través de Smad2 y Smad3, inhibe la proliferación y migración de las CE (36). Las R-Smad activadas interactúan con la Smad4 (una Co-Smad) formando un complejo que se transloca al núcleo, donde regula la actividad transcripcional de una serie de dianas génicas (37). Finalmente, las I-Smad, la Smad6 y la Smad7, impiden la activación de las R-Smad al competir por el receptor, induciendo su degradación o desfosforilando el receptor de tipo I (38-40).

La endoglina, que se expresa de forma predominante en las CE vasculares, se considera actualmente un receptor de TGF- $\beta$ de tipo III (T $\beta$ R-III) que sólo se une a ligandos cuando está asociada al T $\beta R$-II (8). Se ha observado que la endoglina es necesaria para la señalización del TGF- $\beta$ /ALK1 (41). En cambio, Pece-Barbara y cols. han publicado recientemente que las células sin endoglina proliferaron más rápidamente y mostraron más actividad en la vía de ALK1/Smad1, pero sin modificar la de ALK5/Smad2 (42). A pesar de estos hallazgos contradictorios, se acepta que el nivel de expresión de la endoglina determina la capacidad de crecimiento de las CE. En ausencia de endoglina, las CE no crecen y la señalización de ALK1 queda suprimida mientras se estimula la de ALK5. Por el contrario, la sobreexpresión de endoglina regula a la baja la señalización del TGF- $\beta$ /ALK5 al inhibir la actividad transcripcional de Smad3 (43). La endoglina podría así servir de regulador del crecimiento de las $\mathrm{CE}$ mediado por el TGF- $\beta$ al estimular la señalización del TGF- $\beta$ /ALK1 e inhibir indirectamente el TGF- $\beta$ /ALK5, promoviendo así la fase de activación de la angiogénesis (36). Un rasgo relevante de la señalización de la ALK1 es su estricta dependencia de la actividad de la ALK5, como se observa en las células endoteliales con déficit de ALK5 (44). No obstante, sigue sin estar clara la manera en que la endoglina influye en la señalización del TGF$\beta /$ ALK1; la endoglina podría estar implicada en la formación de complejos heteroméricos entre ALK1 y ALK5, o en el reclutamiento de la Smad1/5 hacia ALK1 (Fig. 2). Se necesitan más estudios para clarificar estas cuestiones. 

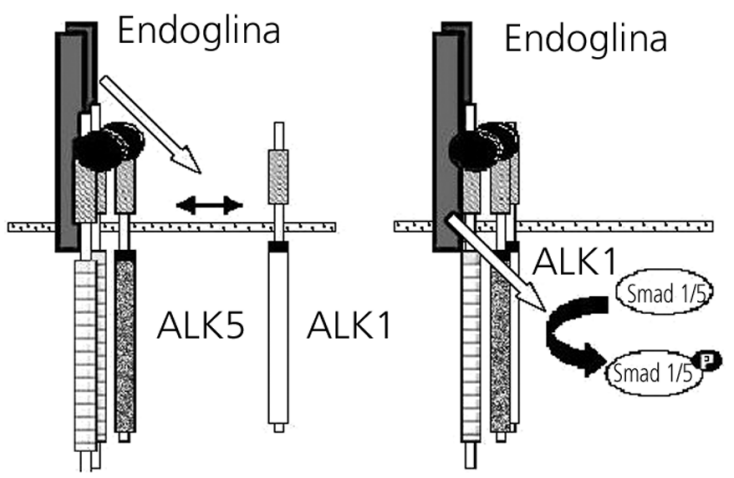

Fig. 2. Modelo hipotético de la función de la endoglina. La endoglina podría intervenir en la formación de complejos heteroméricos entre ALK1 y ALK5, y en el reclutamiento de Smad1/5 hacia ALK1, lo que llevaría a la fosforilación (P) del complejo Smad 1/5.

\section{Endoglina y fibrogénesis}

La fibrogénesis es un proceso complejo que se caracteriza por interacciones fuertemente reguladas entre distintos tipos de células capaces de sintetizar y secretar una serie de proteínas de la matriz extracelular (MEC), y factores de crecimiento capaces de inducir la activación, proliferación y diferenciación de las células potencialmente fibrogénicas. La capacidad de determinados tipos de células, como las mesangiales del glomérulo (CMG) y las estrelladas del hígado (CEH), para modular su fenotipo proliferativo y secretar MEC habla en favor de su papel fundamental en el desarrollo y la progresión de la fibrosis renal y hepática, respectivamente $(45,46)$. Estos aspectos de la conducta de las CMG y las CEH se pueden modificar por efecto del TGF- $\beta$, una citoquina multifuncional que regula la activación, la proliferación y la morfogénesis $(47,48)$. Así, se ha observado que el TGF- $\beta$ es un mediador clave de la fibrosis renal y hepática tanto en los modelos animales experimentales como en las enfermedades humanas $(49,50)$.

Desde 1996 (26) se sabe que la endoglina es capaz de modular varias respuestas celulares al TGF- $\beta 1$ sin interferir con la unión o la degración de sus ligandos, lo que indica su posible capacidad reguladora sobre la síntesis de proteínas de la MEC inducida por el TGF- $\beta 1$. Entre las células residentes en el riñón, las CMG constituyen dianas bien definidas para el TGF- $\beta$ y podrían desempeñar un papel central en la aparición de la fibrosis glomerular. En apoyo de esta idea, se vio que la endoglina se expresa en las CMG y que esta expresión estaba inducida al alza por el TGF- $\beta 1(51,52)$. Además, se ha observado que la expresión de endoglina reduce la acumulación de colágeno tanto basal como estimulado por el TGF- $\beta 1$ en las CMG humanas y en los mioblastos de rata transfectados con endoglina (52-54), lo que indica que la endoglina podría tener una función importante en la patogenia de la fibrosis renal.

En cuanto a la fibrogénesis hepática, uno de los elementos clave de este proceso es la activación de las $\mathrm{CEH}$, que lleva a la diferenciación de este precursor fibrogénico hacia el fenotipo miofibroblástico productor de MEC (55). Numerosos estudios han identificado el TGF- $\beta$ como la principal citoquina profibrogénica, que al actuar conjuntamente con otros factores de crecimiento promueve la diferenciación de las CEH en miofibroblastos (MFB) (56-58). Para que la respuesta celular mediada por el TGF- $\beta$ sea eficaz se necesita la expresión de T $\beta$ R-I y II en la membrana, así como la del receptor accesorio de tipo III llamado endoglina. Curiosamente, a diferencia de las $\mathrm{CEH}$, los MFB no reaccionan inhibiendo su crecimiento y sintetizando proteínas de la MEC después de tratarlas con TGF- $\beta 1$ (59), lo que indica que el patrón de expresión de los receptores de TGF- $\beta$ podría alterarse durante la diferenciación fenotípica de la CEH en MFB. Sin embargo, se ha notificado que los receptores T $\beta R$-I, II y de tipo III se expresan en ambos tipos de células $(60,61)$.

En cuanto a la función de la endoglina en las CEH y los MFB, por el momento sólo podemos hacer especulaciones. La opinión actual acerca de la señalización del TGF- $\beta$ en las CEH indica que en estas células existe un uso diferente de los receptores de TGF- $\beta$ ALK1 y ALK5, de forma parecida a lo que ocurre en las CE. Esta idea se basa en varios estudios que han observado que ALK1 y ALK5 se expresan en las CEH $(62,63)$. Aún están por definir las bases moleculares que controlan la actividad señalizadora de ALK1 y de ALK5 en las CEH, que podría depender de las concentraciones de ligando activo, el estado de activación de las CEH y el nivel de expresión de los distintos receptores del TGF- $\beta$ en la superficie de estas células a lo largo del proceso de diferenciación. En este sentido, como se dijo anteriormente, se ha demostrado que los receptores T $\beta$ R-I y II se expresan constantemente en las CEH en diferenciación (60), pero más recientemente Wiercinska y cols. aportaron pruebas experimentales de que el nivel de expresión de la endoglina (receptor de TGF- $\beta$ de tipo III) aumentaba progresivamente durante la diferenciación de las CEH en MFB (63). Esto último está avalado por estudios in vivo que muestran una marcada expresión de endoglina en los MFB septales de los pacientes con fibrosis hepática avanzada (Fig. 3A), mientras que la endoglina se ha observado fundamentalmente en las células que revisten los sinusoides en el hígado normal (Fig. 3B) (64). De acuerdo con estos datos resulta concebible que la endoglina pudiera desempeñar un papel importante al influir sobre la señalización del TGF- $\beta$ en las CEH/los MFB, favoreciendo las vías de señalización de ALK1 o ALK5 de manera parecida a lo que ocurre en las CE, modificando de alguna manera las respuestas fibrogénicas mediadas por el TGF- $\beta$. Aunque el efecto inhibitorio de la endoglina so- 

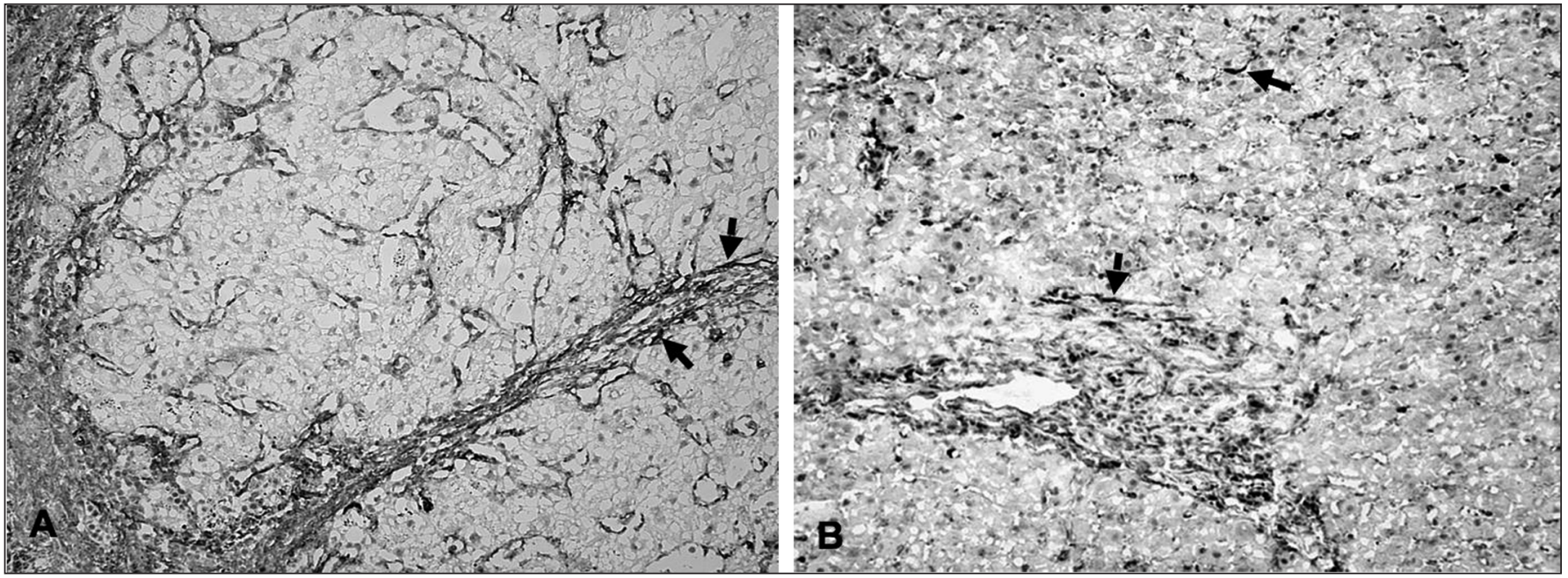

Fig. 3. Detección inmunohistoquímica de la endoglina en muestras congeladas de biopsia hepática. En los pacientes con fibrosis avanzada, la endoglina se expresa intensamente en los miofibroblastos septales (flechas) (Recuadro A, magnificación original de 300x). En los hígados histológicamente normales, la endoglina se detecta en algunas células dispersas del revestimiento sinusoidal (flechas) (Recuadro B, magnificación original de 300x).

bre la vía de ALK5 se ha confirmado en distintos tipos de células $(41,65)$, de momento no hay datos concluyentes sobre el papel funcional de la endoglina en las CEH. Dilucidar el mecanismo exacto por el que la endoglina podría favorecer una determinada vía de señalización TGF$\beta /$ Smads en las CEH aumentaría nuestro grado de compresión de la compleja red que forman las respuestas biológicas inducidas por el TGF- $\beta$ y que llevan a la diferenciación de las CEH en MFB, el paso principal del proceso hepático de fibrogénesis, y también aportaría información importante sobre dianas moleculares que pudieran emplearse para diseñar tratamientos antifibrinogénicos más específicos.

\section{AGRADECIMIENTOS}

Este trabajo se ha financiado en parte mediante una beca concedida a Carmelo García Monzón por el Instituto de Salud Carlos III (PI: 06/0221 y CIBERehd).

\section{BIBLIOGRAFÍA}

1. Gougos A, Letarte M. Identification of a human endothelial cell antigen with monoclonal antibody $44 \mathrm{G} 4$ produced against a pre-B leukemic cell line. J Immunol 1988; 141: 1925-33.

2. Lastres P, Bellón T, Cabañas C, Sánchez-Madrid F, Acevedo A, Gougos A, et al. Regulated expression on human macrophages of endoglin, an Arg-Gly-Asp-containing surface antigen. Eur J Immunol 1992; 22: 393-7.

3. Bürhing HJ, Müller CA, Letarte M, Gougos A, Saalmüller A, von Agthoven AJ, Busch FW. Endoglin is expressed on a subpopulation of inmature erythroid cells of normal human bone marrow. Leukemia 1991; 5: 841-7.

4. Gougos A, St Jacques S, Greaves A, O'Connell PJ, d'Apice AJF, Bürhing HJ, et al. Identification of distinct epitopes of endoglin, an RGD-containing glycoprotein of endothelial cells, leukemic cells, and syncytiotrophoblasts. Intern Immunol 1992; 4: 83-92.
5. St Jacques S, Cymerman U, Pece N, Letarte M. Molecular characterization and in situ localization of murine endoglin reveal that it is a transforming growth factor- $\beta$ binding protein of endothelial and stromal cells. Endocrinology 1994; 134: 2645-57.

6. Fernández-Ruiz E, St Jacques S, Bellón T, Letarte M, Bernabéu C. Assignment of the human endoglin gene (END) to chromosome 9q34qter. Cytogenet Cell Genet 1993; 64: 204-7.

7. McAllister KA, Grogg KM, Johnson DW, Gallione CJ, Baldwin MA, Jackson CE, et al. Endoglin, a TGF- $\beta$ binding protein of endothelial cells, is the gene for hereditary haemorrhagic telangiectasia type 1 . Nature Genet 1994; 8: 345-51.

8. Cheifetz S, Bellón T, Calés C, Vera S, Bernabéu C, Massagué J, et al. Endoglin is a component of the transforming growth factor- $\beta$ receptor system in human endothelial cells. J Biol Chem 1992; 267: 19027-30.

9. Duff SE, Li C, Garland JM, Kumar S. CD105 is important for angiogenesis: Evidence and potential applications. FASEB J 2003; 17: 98492.

10. Bourdeau A, Dumont DJ, Letarte M. A murine model of hereditary hemorrhagic telangiectasia. J Clin Invest 1999; 104: 1343-51

11. Li C, Hampson IN, Hampson L, Kumar P, Bernabeu C, Kumar S $\mathrm{CD} 105$ antagonizes the inhibitory signaling of transforming growth factor $\beta 1$ on human endothelial vascular cells. FASEB J 2000; 14: 55-64.

12. Sorensen LK, Brooks BS, Li DY, Umess LD. Loss of distinct arterial and venous boundaries in mice lacking endoglin, a vascular-specific TGFbeta coreceptor. Dev Biol 2003; 261: 235-50.

13. Fonsatti E, Altomonte M, Nicostra MR, Natali PG, Maio M. Endoglin (CD105): A powerful therapeutic target on tumor-associated angiogenic blood vessels. Oncogene 2003; 22: 6557-63.

14. Maio M, Altomonte M, Fonsatti E. It is the prime time for endoglin (CD105) in the clinical setting? Cardiovasc Res 2006; 69: 781-3.

15. Roy-Chaudhury P, Simpson JG, Power DA. Endoglin, a transforming growth factor-beta-binding protein, is upregulated in chronic progressive renal disease. Exp Nephrol 1997; 5: 55-60.

16. García-Monzón C, Sánchez-Madrid F, García-Buey L, García-Arroyo A, García-Sánchez-A, Moreno-Otero R. Vascular adhesion molecule expression in viral chronic hepatitis: Evidence of neoangiogenesis in portal tracts. Gastroenterology 1995; 108: 231-41.

17. Gougos A, Letarte M. Primary structure of endoglin, an RGD-containing glycoprotein of human endothelial cells. J Biol Chem 1990; 265: 8361-4.

18. Bellón T, Corbi A, Lastres P, Cales C, Cebrian M, Vera S, et al. Identification and expression of two forms of the transforming growth factorbeta-binding protein endoglin with distinct cytoplasmic regions. Eur J Immunol 1993; 23: 2340-5.

19. Bork P, Sander C. A large domain common to sperm receptors (ZP2 and ZP3) and TGF-beta type III receptor. FEBS letters 1992; 300: 237-40. 
20. Jovine L, Darie CC, Litscher ES, Wassarman PM. Zona pellucida domain proteins. Annu Rev Biochem 2005; 74: 83-114.

21. Guerrero-Esteo M, Lastres P, Letamendia A, Pérez-Álvarez MJ, Langa C, López IA, et al. Endoglin overexpression modulates cellular morphology, migration, and adhesion of mouse fibroblasts. Eur J Cell Biol 1999; 78: 614-23.

22. Guo B, Rooney P, Slevin M, Li C, Parameshwar S, Liu D, et al. Overexpression of CD105 in rat myoblasts: Role of CD105 in cell attachment, spreading and survival. Int J Oncol 2004; 25: 285-91.

23. Llorca O, Trujillo A, Blanco FJ, Bernabéu C. Structural model of human endoglin, a transmembrane receptor responsible for hereditary hemorrhagic telangiectasia. J Mol Biol 2007; 365 (3): 694-705.

24. Jovine L, Qi H, Williams Z, Litscher ES, Wassarman PM. The ZP domain is conserved module for polymerization of extracellular proteins. Nature Cell Biol 2002; 4: 457-61.

25. Abdalla SA, Letarte M. Hereditary haemorrhagic telangiectasia: Current views on genetics and mechanisms of disease. J Med Genet 2006; 43: 97-110.

26. Lastres P, Letamendía A, Zhang H, Rius C, Almendro N, Raab U, et al. Endoglin modulates cellular responses to TGF- $\beta 1$. J Cell Biol 1996; 131: 1109-21.

27. Fernández-L A, Sanz-Rodríguez F, Blanco FJ, Bernabéu C, Botella LM. Hereditary hemorrhagic telangiectasia, a vascular dysplasia affecting the TGF- $\beta$ signaling pathway. Clin Med Res 2006; 4: 66-78.

28. Jerkic M, Rodríguez-Barbero A, Prieto M, Toporsian M, Pericacho M, Rivas-Elena JV, et al. Reduced angiogenic responses in adult Endoglin heterozygous mice. Cardiovascular Res 2006; 69: 845-54.

29. McDonald MT, Papenberg KA, Ghosh S, Glatfelter AA, Biesecker BB, Helmbold EA, et al. A disease locus for hereditary haemorrhagic telangiectasia maps to chromosome 9q33-34. Nat Genet 1994; 6: 197 204.

30. Shovlin CL, Hughes JM, Tuddenham EG, Temperley I, Perembelon YF, Scott J, et al. A gene for hereditary haemorrhagic telangiectasia maps to chromosome 9q33-34. Nat Genet 2004; 6: 205-9.

31. Johnson DW, Berg JN, Baldwin MA, Gallione CJ, Marondel I, Yoon $\mathrm{SJ}$, et al. Mutations in the activin receptior-like kinase 1 gene in hereditary haemorrhagic telangiectasia type 2 . Nature Genet 1996; 13: 18995.

32. Cole SG, Begbie ME, Wallace GM, Shovlin CL. A new locus for hereditary haemorrhagic telangiectasia (HHT3) maps to chromosome 5. J Med Genet 2005; 42: 577-82.

33. Yamashita H, ten Dijke P, Franzen P, Miyazono K, Heldin CH. Formation of hetero-oligomeric complexes of type I and type II receptors for transforming growth factor beta. J Biol Chem 1994; 269: 20172-8.

34. Derynck R, Zhang YF. Smad-dependent and Smad-independent pathways in TGF-beta family signalling. Nature 2003; 425: 577-84.

35. Goumans MJ, Valdimarsdottir G, Itoh S, Rosendahl A, Sideras P, ten Dijke P. Balancing the activation state of the endothelium via two distinct TGF-beta type I receptors. EMBO J 2002; 21: 1743-53.

36. Goumans MJ, Lebrin F, Valdimarsdottir G. Controlling the angiogenic switch: A balance between two distinct TGF- $\beta$ receptor signaling pathways. Trends Cardiovasc Med 2003; 13: 301-7.

37. ten Dijke P, Hill CS. New insights into TGF- $\beta$-Smad signaling. Trens Biochem Sci 2004; 29: 265-73.

38. Nakao A, Imamura T, Souchelmytskyi S, Kawabata M, Ishisaki A, Oeda E, et al. TGF-beta receptor-mediated signalling through Smad2, Smad3 and Smad4. EMBO J 1997; 16: 5353-62.

39. Suzuki C, Murakami G, Fukuchi M, Shimanuki T, Shikauchi Y, Imamura $\mathrm{T}$, et al. Smurfl regulates the inhibitory activity of Smad7 by targeting Smad7 to the plasma membrane. J Biol Chem 2002; 277 : 3991925.

40. Shi W, Sun C, He B, Xiong W, Shi X, Yao D, et al. GADD34-PPIc recruited by Smad7 dephosphorylates TGF-beta type I receptor. J Cell Biol 2004; 164: 291-300.

41. Lebrin F, Goumans MJ, Jonker L, Carvalho RL, Valdimarsdottir G, Thorikay M, et al. Endoglin promotes endothelial cell proliferation and TGF-beta/ALK1 signal transduction. EMBO J 2004; 23: 4018-28.

42. Pece-Barbara N, Vera S, Kathirkamathamby K, Liebner S, Di Guglielmo GM, Dejana E, et al. Endoglin null endothelial cells proliferate faster and are more responsive to transforming growth factor beta1 with higher affinity receptors and a activated Alk1 pathway. J Biol Chem 2005; 280: 27800-8.

43. Guo B, Slevin M, Li C, Parameshwar S, Liu D, Kumar P, et al. CD105 inhibits transforming growth factor-beta-Smad3 signalling. Anticancer Res 2004; 24: 1337-45.

44. Goumans MJ, Valdimarsdottir G, Itoh S, Lebrin F, Larsson J, Mummery $\mathrm{C}$, et al. Activin receptor-like kinase (ALK)1 is an antagonistic mediator of lateral TGFbeta/ALK5 signaling. Mol Cell 2003; 12: 81728.

45. Strutz F, Müller GA, Neilson EG. Transdifferentiation: A new angle on renal fibrosis. Exp Nephrol 1996; 4: 267-70.

46. Reeves HL, Friedman SL. Activation of hepatic stellate cells -a key issue in liver fibrosis. Front Biosci 2002; 7: 808-26.

47. Border WA, Ruoslahti E. Transforming growth factor-beta in disease: The dark side of tissue repair. J Clin Invest 1992; 90: 1-7.

48. Roberts AB, Sporn MB. Physiological actions and clinical applications of transforming growth factor-beta (TGF-beta). Growth Factors 1993; 8: 1-9.

49. Ketteler M, Noble NA, Border WA. Transforming growth factor-beta and angiotensin II: The missing link from glomerular hyperfiltration to glomerulosclerosis? Annu Rev Physiol 1995; 57: 279-95.

50. Gressner AM, Weiskirchen R, Breitkopf K, Dooley S. Roles of TGF- $\beta$ in hepatic fibrosis. Front Biosci 2002; 7: 793-807.

51. Rodríguez-Barbero A, Obreo J, Eleno N, Rodríguez-Peña A, Düwel A, Jerkic M, et al. Endoglin expression in human and rat mesangial cells and its upregulation by TGF- $\beta 1$. Biochem Biophys Res Com 2001; 23: 142-7.

52. Díez-Marqués L, Ortega-Velázquez R, Langa C, Rodríguez-Barbero A, López-Novoa JM, Lamas S, et al. Expression of endoglin in human mesangial cells: Modulation of extracellular matrix synthesis. Biochem Biophys Acta 2002; 158: 36-44.

53. Obreo J, Díez-Marqués L, Lamas S, Duwell A, Eleno N, Bernabéu C, et al. Endoglin expression regulates basal and TGF-beta1-induced extracellular matrix synthesis in cultures L6E9 myoblasts. Cell Physiol Biochem 2004; 14: 301-10.

54. Rodríguez-Barbero A, Obreo J, Álvarez-Muñoz P, Pandiella A, Bernabéu C, López-Novoa JM. Endoglin modulation of TGF- $\beta 1$-induced collagen synthesis is dependent on ERK1/2 MAPK activation. Cell Physiol Biochem 2006; 18: 135-42.

55. Gressner AM, Weiskirchen R. Modern pathogenetic concepts of liver fibrosis suggest stellate cells and TGF- $\beta$ as major players and therapeutic targets. J Cell Mol Med 2006; 10: 76-99.

56. Cassiman D, Roskams T. Beauty is in the eye of the beholder: Emerging concepts and pitfalls in hepatic stellate cells research. J Hepatol 2002; 37: 527-35.

57. Gressner AM. Perisinusoidal lipocytes and fibrogenesis. Gut 1994; 35 : 1331-3.

58. Bataller R, Brenner DA. Liver fibrosis. J Clin Invest 2005; 115: 209-18.

59. Bachem MG, Meyer DH, Schafer W, Riess U, Melchior R, Sell KM, et al. The response of rat liver perisinusoidal lipocytes to polypeptide growth regulator changes with their transdifferentiation into myofibroblasts-like cells in culture. J Hepatol 1993; 18: 40-52.

60. Dooley S, Delvoux B, Lahme B, Mangasser-Stephan K, Gressner AM. Modulation of transforming growth factor $\beta$ pesponse and signaling during transdifferentiation of rat hepatic stellate cells to myofibroblasts. Hepatology 2000; 31: 1094-106.

61. Meurer SK, Tihaa L, Lahme B, Gressner AM, Weiskirchen R. Identification of endoglin in rat hepatic stellate cells: New insights into transforming growth factor $\beta$ receptor signaling. J Biol Chem 2005; 280: 3078-87.

62. Dooley S, Delvoux B, Streckert M, Bonzel L, Stopa M, ten Dijke P, et al. Transforming growth factor $\beta$ signal transduction in hepatic stellate cells via Smad2/3 phosphorylation, a pathway that is abrogated during in vitro progression to myofibroblasts. FEBS letters 2001; 502: 4-10.

63. Wiercinska E, Wickert L, Denecke B, Said HM, Hamzavi J, Gressner AM, et al. Id1 is a critical mediator in TGF- $\beta$-induced transdifferentiation of rat hepatic stellate cells. Hepatology 2006; 43: 1032-41.

64. Clemente M, Núñez O, Lorente R, Rincón D, Matilla A, Salcedo M, et al. Increased intrahepatic and circulating levels of endoglin, a TGF- $\beta 1$ co-receptor, in patients with chronic hepatitis $\mathrm{C}$ virus infection: Relationship to histological and serum markers of hepatic fibrosis. J Viral Hepat 2006; 13: 625-32.

65. Scherner O, Meurer SK, Tihaa L, Gressner AM, Weiskirchen R. Endoglin differentially modulates antagonistic transforming growth factor-beta1 and BMP-7 signaling. J Biol Chem 2007; 282: 13934-43. 